\title{
Infrastructure and Business Model for Universal Broadband Access in Developing Regions: The Ceara State Digital Belt
}

\author{
Cid F. Gomes ${ }^{1}$, Fernando C. Gomes ${ }^{1,2}$, and Marcial P. Fernandez ${ }^{3}$ \\ 1 Ceara State Government, \\ Centro Administrativo Barbara de Alencar, 60811 Fortaleza, Brazil \\ cidgomes@gabgov . ce.gov . br \\ 2 Computer Science Department, Universidade Federal do Ceara, \\ Campus do Pici, Bloco 910, 60455 Fortaleza, Brazil \\ carvalho@lia.ufc.br \\ 3 Computer Network and Information Security Lab, \\ Universidade Estadual do Ceara, \\ Campus do Itaperi, Av. Paranjana 1700, 60740 Fortaleza, Brazil \\ marcial@larces.uece.br
}

\begin{abstract}
With regard to digital services access, many rural and remote urban area in developing countries are underserved, if served at all. In a monopolized environment, telecommunications are of low quality and costly. Broadband Internet and other digital services are restricted to small percentage of people. In some cases the operator prefers to pay fines instead of providing services to remote areas. In this paper we present an infrastructure together with its business model that is being installed in the Brazilian Ceara state. This infrastructure was entirely constructed by the state government, but the operational costs (OPEX) will be paid by investors willing to share data transportation. Different groups will be chosen among interested investors by public auction, in order to enforce competition. Moreover, a new state company will be created that will offer low cost data transportation services, assuring that high bandwidth will be available to more than $80 \%$ of the state population.
\end{abstract}

Keywords: Optical Networks, Wireless Communications, Telecommunication Policy-Developing Countries.

\section{Introduction}

Broadband is a vital driver of economic growth, not only in the demand it generates directly, but also in gains in economic efficiency and the creation of new applications. Waverman, Meschi and Fuss 9 , confirm that the GDP growth impact of mobiles is large in both developed and developing countries, but around twice as important in the latter group. The policy implication of their results for developing countries is clear: it will be worth investing in telecommunications to get close to universal service. Governments around the world are seeking to 
improve digital inclusion and maximize the economic benefits of Internet access, Distance Learning, Telemedicine, Electronic Entertainment, Security Systems, etc. These examples illustrate only a few of the ways in which broadband technology is changing our lives.

The United States President Obama recently signed into law the $\$ 787$ billion stimulus package, which includes $\$ 7.2$ billion for broadband grant and loan programs. France has determined that apartments and offices in new buildings must be connected by optical fiber. Other governments around the world are seeking to improve digital inclusion as they strive to create modern information societies.

As noted in ITUs Trends in Telecommunication Reform 2008, the first approach that operators can adopt to roll out advanced connectivity is the deployment of fibre as rapidly as possible [1].

In this paper we present the infrastructure (fiber backbone and wireless last mile) deployed by the state government in Ceara, Brazil. Moreover, we propose a sustainable business model that will be applied in order to bring competition to remote areas and, as a consequence, increase the offer of affordable digital services to the population.

\section{Environment}

Most of the country lack telecommunications infrastructure.

\subsection{Brazilian States Are Underserved}

Much of the data communication for the final leg of delivering connectivity from a communications provider to a customer (also known as last mile) in Brazil relies on ADSL (Asynchronous Digital Subscriber Line) technology, which uses the fixed telephony network infrastructure. This refers to the main obstacle to the development of telecommunications in the country: the monopoly on fixed telephony. In every region of the country, only one company holds the ADSL infrastructure. On the top of that, since the monopoly does not invest on deploying fiber, many Brazilian states lack a wired optical fiber backbone and updated ADSL. As a consequence, most of the country suffers with low speed narrow bandwidth and high telecom costs 246].

In the monopoly environment, the sole company that holds the infrastructure does not see broadband connection as an essential service that must be spread out, even to low income population. They see it as a highly profitable business, for which its infrastructure should be kept available to those, and only to those, who can afford to pay very high connectivity prices. Competition among broadband providers would be the best way to lower costs and to have the state-of-the-art communication technology available.

Ceara is a Brazilian state located in the northeastern developing region that counts 8 million inhabitants spread out in a 148,825 $\mathrm{km}$ area. Estimates show that in 2008 only $3 \%$ of the state population has broadband access (equal or greater than $1 \mathrm{Mbps}$ ), most of them live at the capital, Fortaleza. These facts reveal that a huge rural area is underserved, if served at all. 


\subsection{Brazilian Broadband among World's Worst}

Oxford and Oviedo universities recently presented a broadband quality joint study showing that Brazils Broadband Quality Score (BQS) ranks 40th among 42 countries [2. If one considers the Northeast of Brazil only, he or she would obtain even worst results. As a matter of fact, according to the Brazilian Internet Steering Committee 2009 survey [3], Internet access (low speed bandwidth) in Northeast is available only to $7 \%$ of the population. These facts reveal that people in the region have no ability to benefit from todays and next-generation web applications and services.

The Ceara state contributes only to $2 \%$ of the Brazilian GDP. Its population is about 8,7 million people, including $89,7 \%$ of urban population. The state telecommunication company has been privatized in 1998. Like other Brazilian states, although there is the last mile monopoly, four cellular telephony operators provide cell phone lines throughout the state. They use long distance radio backhaul for communication between cities. However, since the radio infrastructure available does not allow higher speed communication, they offer $3 \mathrm{G}$ service effective only to Fortaleza, the state capital.

Facilitating the widespread deployment of next-generation broadband Internet with download speeds of at least 20 Megabits per second (Mbps), and ideally 50 Mbps or upwards will enable the emergence of a whole host of online applications and services, many of which we can barely imagine today [5/7/8].

\subsection{Costs Are High}

The Ceara state government communications needs are comprehensive. Schools, police stations, hospitals, fiscal agents, and so on, have to be connected through a 3.000 nodes data network, in order to access e-gov applications and Internet. Since there is no competition, communication service is not only expensive, but also low quality. For example, most of the schools have only 64 Kbps. Government pays for each school link R $\$ 700.00$ monthly (approximately US $\$ 300.00$, as of February 2010). The annual data link bill amounts to $\mathrm{R} \$ 20$ million (approximately US\$ 9 million per annum) altogether. Besides, one will find low speed broadband ( 1 to $2 \mathrm{Mbps}$ ) only in five out of 185 state counties.

\section{The Digital Belt: An Infrastructure for Governance and Development}

The government has started to launch a digital belt around the state, composed of a 3,000 kilometers optical fiber redundant ring and ramifications. The states digital belt will initially cover $82 \%$ of the population. It has two main roles:

I. To fulfill the government needs in the 50 most populated cities;

II. To give telecom carriers and service providers incentive to use and share the infrastructure, in order to foster the digital inclusion across the state, and create an environment in which broadband innovation and competition could flourish. 
The states Digital Belt will cost R $\$ 65$ million (approximately US\$ 36 million), and will be finished by June 2010 .

By making it possible to access, use, and share information, news, and entertainment with ever increasing speed, broadband knits geographically-distant individuals and businesses more closely together, increases productivity, and enriches quality of life. In so doing, it fuels economic growth and job creation that, in turn, provide unparalleled new opportunities for citizens.

Besides, states economy must benefit from broadband connection. Population has to access ubiquitous, lower price digital services. Business, societies, lowincome communities

Connectivity with sustainability is the central idea behind the Digital Belt. As a matter of fact, government agencies will not operate the infrastructure. It should be sustained and operated by private companies, interested in providing digital IT services. Nevertheless, it is not evident how to transfer the infrastructure to the companies, so one could assure competition among them. Besides, it is important to give broadband Internet access the low-income population.

\subsection{Technological Challenges}

To specify the technology used in the Ceara State Digital Belt it was needed to consider several factors. Many of these factors are not exclusive to the particular situation of the state of Ceara, but are also present in other developing countries.

The first point was to choose the appropriate technology for the network topology. As we stated, the state of Ceara has a very large geographic area and different population densities. Forty percent of the population lives in the Metropolitan Region of Fortaleza, which represents less than $4 \%$ of the land area of the state. So the technologies chosen should encompass both situations: a densely populated area and a huge sparse population area.

The second point was to choose a technology that could support the connectivity demands for, at least, 10 years. At this point we must mention that an important fact is the government network, contracted from operators. Therefore, there are no legacy technologies to be considered, giving freedom to choose the best technology.

Finally, the third important point is to choose technologies with low cost of installation and operation. As the major goal of the government is the population coverage, as much cheaper is the technology chosen, the increase of coverage is achieved with the same budget. Low cost operation allows a longer use of the network, with less chance to being restricted during an economic crisis, for instance.

Optical Backbone. The backbone technology adopted is the fiber optic, both in metropolitan and rural areas. We agree that optical technology is suitable to permit long hauls transmission and almost infinite increase of transmission capacity. Building a network with fiber optics is not the cheapest alternative, but considering the transmission quality and capacity scalability achieved, is a valuable investment. 
As Data Link technology Giga-Ethernet was adopted. As the main objective is the connectivity and Internet access, Ethernet technology is quite appropriate. The Ethernet evolution in recent years allowed the extension of the distance achieved with this technology, that is also called Metro-Ethernet and CarrierEthernet.

To ensure recovery in case of failure, the entire network uses the ring architecture, moreover, Ethernet Automatic Protection Switching (EAPS) protocol was adopted to ensure failover in less than $50 \mathrm{~ms}$, which is in compliance with to recovery requirements of telecommunications network based on Synchronous Digital Hierarchy (SDH). Another architectural approach was the implementation of a double ring as shown in Figure 1.

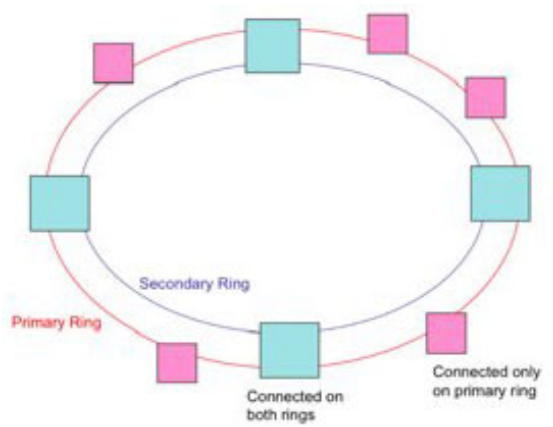

Fig. 1. Redundant double ring, implemented by frequency multiplex

The most considerable problem in a ring Metro-Ethernet network is the dependence of all nodes that should be active to ensure redundancy, because if two nodes turn off, one sector of the ring comes down. Thus, we chose some points with better infrastructure and big traffic demand, to connect a second ring. As they are larger sites, we offered a data rate twice than the others, and, in these places, there are also better infrastructure 24 hour a day. If two intermediate nodes are disconnected, there will be another way through the second ring, improving network reliability. As the second fiber is on the same cable, when the cable break both primary and secondary ring will be interrupted, but the experience shows that most problems on the network were due the shutdown of switches in nodes with less infrastructure, like short time of UPS and lack of qualified personnel.

The optical solutions adopted were different in the metropolitan and rural area. In the metropolitan area Ethernet switches with optical interfaces for long distance were used. As each node is $2 \mathrm{Km}$ to $5 \mathrm{Km}$ far from each other, 1 GBPS LX interfaces was used (up to $10 \mathrm{Km}$ ).

Within the rural area of state, the distances are significantly higher, despite an average of $40 \mathrm{~km}$ between nodes, many spans have more than $80 \mathrm{~km}$, beyond the reach of ZX optical interfaces in switches (typically up to $80 \mathrm{Km}$ ). In the rural area we used the Dense Wavelength Division Multiplexing (DWDM) technology. 
Due to support the increase of bandwidth demand and the reduction of optical interfaces costs, we adopted a 10 GBPS basic rate. As all the DWDM equipment is modulated on the ITU-T hierarchy (2.5 GBPS, 10 GBPS, 40 GBPS), the use of 2.5 GBPS becomes inefficient because the maximum Ethernet speedy below 2.5 GBPS is only 1 GBPS and 1.5 GBPS is wasted. A 10 GBPS WDM interface cost only slightly higher than the 2.5 GBPS but allows the transmission of full 10 Gigabit Ethernet.

Like the situation on metro network, in long distance we also adopted the doublering architecture, putting a second ring in some nodes with higher demand and better infrastructure. But unlike metro network, that a second fiber was used, in this situation we used a second lambda to receive the second connection. In the intermediate nodes we adopted Optical Add-Drop Multiplexer (OADM) that does not interrupt the connection of adjacent points even in case of shutdown.

Wireless Last mile. To define the access technology for the last mile we needed to consider different characteristics of population density found in the State. Likewise, it is also necessary to standardize the technology to facilitate the network operation and management and take advantages to get lower cost due to quantity purchased. Considering all technologies available, Pre-Wimax was chose because it fulfils most of the requirements needed.

Another issue is the situation of the frequency licenses for use in Brazil according to the Telecommunication Regulatory Authority (Anatel). The $3.5 \mathrm{GHz}$ frequency auction is in legal dispute since 2006. Therefore, the only frequency available are the license exempt frequencies, such as 5.4 and $5.8 \mathrm{GHz}$. Several Internet providers also use these frequencies, leaving the radiofrequency spectrum congested in various locations. The $5.4 \mathrm{GHz}$ radio offers more channels and is less congested in major cities, but the transmission power is limited, reducing the range. The $5.8 \mathrm{GHz}$ radio has fewer channels, but the higher power increases the range, but it has a very congested spectrum, that brings interference in many places.

However, in 2008, Anatel authorized the use of $4.9 \mathrm{Ghz}$ licensed frequency for use in public safety. As the Digital Belt aims to connect public places in the state, including, hospitals, police and fire stations, these organizations could use this frequency, freeing license-exempt frequencies for other applications, not categorized in this use.

Thus, the Digital Belt Pre-WiMAX network uses $4.9 \mathrm{GHz}$ frequency for public safety. In urban areas, with more users or congested spectrum, the $5.4 \mathrm{GHz}$ frequency was used. As the users density increases, the limited range due to lower power does not cause problems. For point-to-point connection in rural areas with lower density and larger distances, up to $60 \mathrm{Km}$, the $5.8 \mathrm{GHz}$ frequency was used. Usually in these places the spectrum is free and the interference was much smaller.

Figure 2 below shows the optical fiber infrastructure. Its topology takes into account that the number of citizens to be connected to the network must be maximized. As a matter of fact, the infrastructure passes across the biggest cities of the state. 


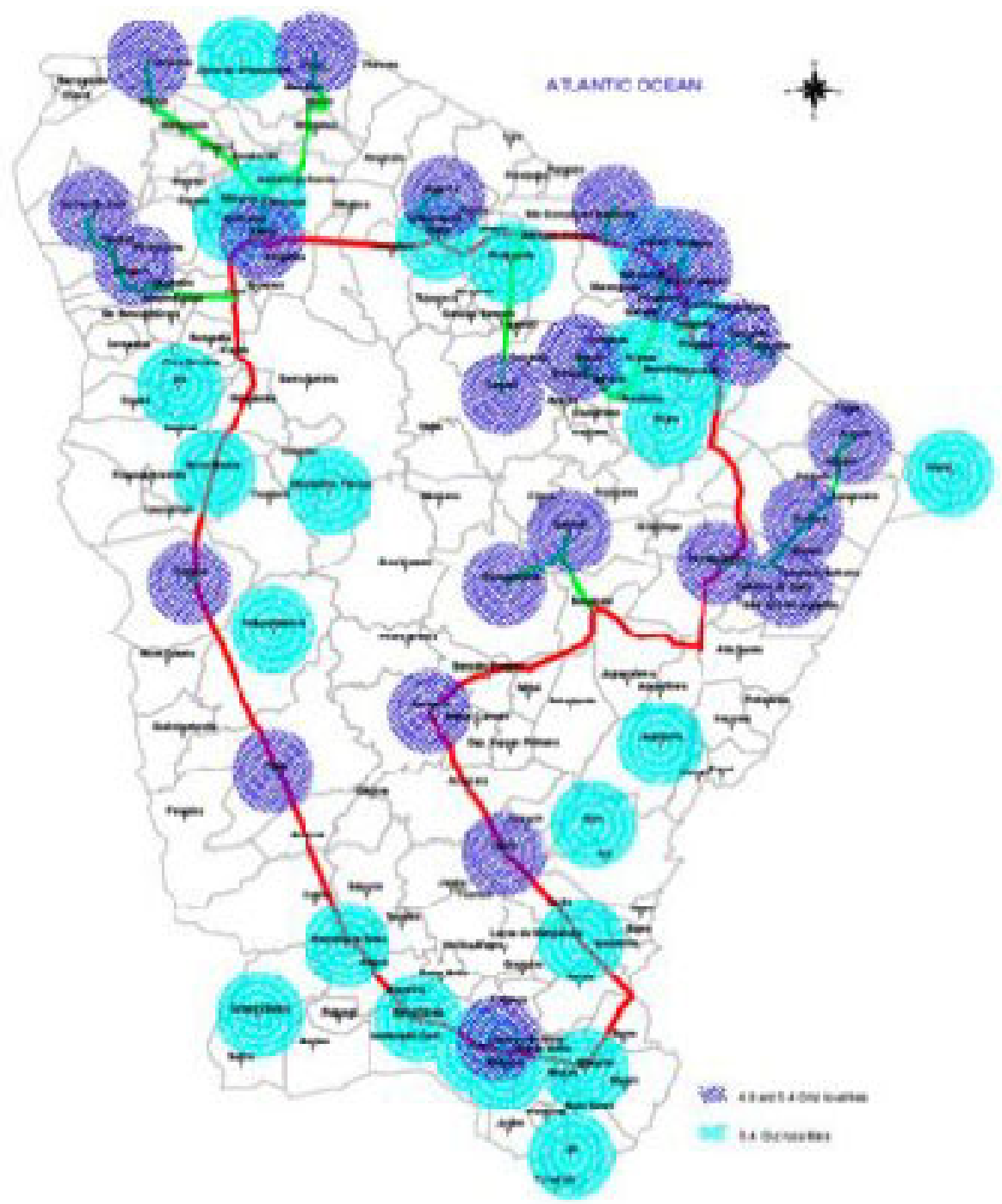

Fig. 2. The Digital Belt. The main redundant ring (red) the ramifications (green) and wireless base stations locations (blue).

\subsection{Partnership with Electricity Utility Company}

All the optical cables are supported by electrical high tension electricity poles. An agreement with the local electricity utility company Coelce has been signed, where the government provides four optical fibers to Coelce, and the company provides power transmission poles, towers, and electrical stations to host network equipment. Coelce intends to deploy a last mile network, using Power Line Connection (PLC) technology. 
The fibre infrastructure comes up in order to fulfill important part of the government communication needs. Initially, the effort will cover $82 \%$ of urban population with Next Generation Network. Public schools, police, fire departments, hospitals, bureaucratic offices all around Ceara will take advantage of this infrastructure.

\section{The Business Model}

Considering the two main foregoing roles of the infrastructure, and the fact that optical fibers will already be illuminated at with ultrahigh speed broadband, many questions arise, for example:

- How to assure competition among service providers?

- Who are the main players?

- What if new service providers want to offer new technology, such as, IPTV, VoD, VoIP?

- How to assure sustainability of the model?

- Will service providers pay for maintain the network?

- Should major service providers hold the infrastructure?

- The players will pay for network expansion?

- How to deal with regulatory obstacles?

Clearly, the government will launch the Digital Belt and then hand it over to service providers. The latter will have to invest in order to provide last mile infrastructure.

The proposed business model depends on four steps to be accomplished by the government:

1. Creation of a joint venture company. This company will be composed of three different investors with equal shares. One of them may be the government itself. The digital belt company has two main purposes: i. to supply highspeed data transportation throughout the state; ii. to manage the network;

2. Promote a bid in order to choose the investors that will participate in the venture. The total amount obtained in the bid will be applied to the new company;

3. Immediately provide 2 GBPS for each private investor in every county of the state.

The government held a workshop on November 2009 with telecoms, Internet services providers and municipalities, in order to gather and discuss propositions to the business model. Many telecom companies, such as, Telemar Norte Leste (largest operator in Brazil), Telecom Italia Mobile, Brazil Telecom, Telefnica, Telmex (Embratel) were present. They appear to be interested in participating in the joint venture.

The Digital Belt is an original enterprise. In order to fulfill governments goals, its business model must be carefully studied and followed up by an experienced team, specialized professionals on feasibility study, telecom billing, and telecommunications technologies. 


\section{Discussion and Conclusion}

The Ceara state government perceived that broadband access is a key value to the population. Large telecom companies would not invest in bringing fiber optics backbone to poor, remote areas. Then the government decided to invest in infrastructure and hand it to the operators in order to achieve almost universal broadband access in a sustainable environment.

In this work we presented the necessary infrastructure (cabled and wireless) and a business plan designed to bring competition to offer affordable digital services to the population.

The infrastructure chosen is based on optical cables and wireless last mile. The business plan calls telecom companies for participation in a new joint venture that offers high-speed data transportation. The government covered all the capital expenditures (CAPEX) in order to build the infrastructures, however, the private sector will cover the operational costs (OPEX).

Since beginning 2008, high-speed broadband demanding services have been funded by the government. Forbidden applications due to low quality dialup connection will become possible. Telemedicine, video-conferencing, videosurveillance, distance learning, remote data access to police cars and firemen are among the applications that will be available to the citizens in a short period of time.

The Digital Belt is an original enterprise. In order to fulfill governments goals, its business model must be carefully studied and followed up by an experienced team, specialized professionals on consultancy in telecommunication market, telecom billing, and state-of-the-art technologies.

\section{References}

1. Biggs, P.: Confronting the Crisis: Its Impact on the ICT Industry. International Telecommunication Union Report (2009)

2. Angani, P., Kim, T., Guleri, U., Misawa, Y., Vicente, M.R.: High-Quality Broadband Essential to Growth of the Worlds Knowledge Economies. University of Oxford and University of Oviedo Joint Report (2008)

3. Brazilian Internet Steering Committee: Survey on the Use of Information and Communication Technologies in Brazil, http://www.cetic.br/tic/2008/index.htm

4. Crandall, R.W., Jackson, C.L.: The $\$ 500$ Billion Opportunity: The Potential Economic Benefit of Widespread Diffusion of Broadband Internet Access. Criterion Economics (2001)

5. Parikh, T.S.: Engineering Rural Development. CACM 52(01) (2009)

6. Fornefeld, M., Delaunay, G., Elixmann, D.: The Impact of Broadband on Growth and Productivity. Micus Management Consulting GmbH (2008)

7. Sein, K.S., Ahmad, I., Harindranath, G.: Sustaining ICT for Development Projects: The Case of Grameenphone CIC. Emerging Markets in Telecommunications. Telektronikk 104(02) (2008)

8. Ezell, S., Atkinson, R., Castro, D., Ou, G.: The Need for Speed: The Importance of Next-Generation Broadband Networks. The Information Technology \& Innovation Foundation Report (2009)

9. Waverman, L., Meschi, M., Fuss, M.: The Impact of Telecoms on Economic Growth in Developing Countries. In: Moving the debate forwards. Vodafone Policy Paper Series, vol. 3 (2005) 